\title{
Estimate of rigidity of greenhouses made of steel pipes
}

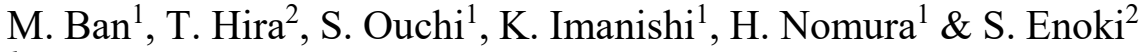 \\ ${ }^{1}$ Faculty of Advanced Engineering, \\ National Institute of Technology, Nara College, Japan \\ ${ }^{2}$ Department of Mechanical Engineering, \\ National Institute of Technology, Nara College, Japan
}

\begin{abstract}
Greenhouses in Japan are usually made of steel pipes and plastic films. A greenhouse comprises arch and straight pipes. The structure is simple, and the construction cost is reasonable. However, typhoons and other disasters have caused considerable damage involving collapse of many structures, including greenhouses. This was caused by the lack of structural strength because of its simplicity. Snows and storms have only brought minor damages in the Nara prefecture until recent years. However, the number of incidents causing damage has been increasing because of the abnormal weather. Therefore, the farmers in the Nara prefecture need strong greenhouses. The basic greenhouse model is the two-dimensional structure of the arch pipe. Some studies conducted stress analysis on this two-dimensional structure. It has been observed that almost all greenhouses have undergone a three-dimensional collapse. This research proposes a new trussbased structure; structural design was conducted using a three-dimensional model. We focused on the rigidity and attempted to analyse the eigenvalues for both the new structure and the conventional one. Consequently, the number of eigenmodes in the new structure was found to be less than the number of those in the conventional one between $0 \mathrm{~Hz}$ and $10 \mathrm{~Hz}$. We consider that the numbers of eigenmodes were transferred to a higher frequency range. The new structure showed good resistance to collapse by resonance.
\end{abstract}

Keywords: greenhouse, pipe structure, eigenvalue analysis. 


\section{Introduction}

Greenhouses in Japan are usually made of steel pipes and plastic films. A greenhouse consists of arch and straight pipes. Greenhouses are widely used for Japanese agriculture because farmers can construct a greenhouse by themselves, and the construction cost is reasonable. However, typhoons and other disasters have caused substantial damage involving collapse of many structures, including greenhouses. These damages were caused by the lack of structural strength because of its simplicity. Snows and storms have caused only minor damages in the Nara prefecture until recent years. However, the number of incidents causing damage has been increasing because of the abnormal weather. Therefore, farmers in the Nara prefecture need strong greenhouses. The typical greenhouse structure was based on the safe construction criterion established in 1999 [1]. The basic model is a two-dimensional (2D) structure of the arch pipe. Some studies have presented an estimation method of the wind load, an experiment, and a stress analysis for the 2D structure [2-4]. It has been observed that almost all greenhouses have undergone a three-dimensional collapse. Accordingly, there have been some attempts of making strong greenhouses by adding parts or changing the shape $[5,6]$. However, these methods are very expensive.

This research proposes a new structure based on the truss structure and the executed structural design using a 3D model. This new structure costs the same as the conventional one. We focus on the rigidity and try to compare both the new structure and the conventional one via simulation.

\section{Greenhouse}

\subsection{Conventional greenhouse structure}

Fig. 1 shows the arch pipe 2D structure of the pipe house, which is the subject of this research.

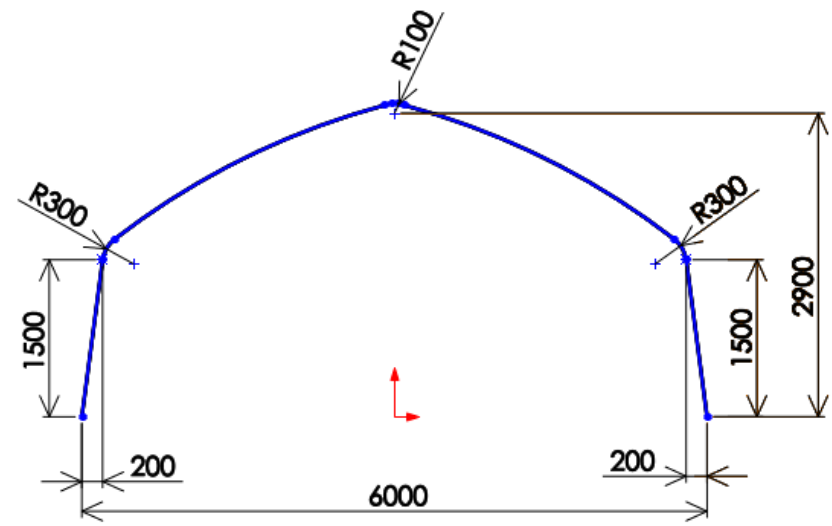

Figure 1: Arched pipe 2D structure of a greenhouse. 
We aligned 20 arch pipes at $500 \mathrm{~mm}$ intervals. The arch pipes were connected by five straight pipes. Fig. 2 shows the $3 \mathrm{D}$ arch pipes. The pipe material was galvanized steel with a Young's modulus of 210,000 MPa and a Poisson's ratio of 0.28 . The pipe has an external diameter of $22.2 \mathrm{~mm}$ and a thickness of $1.2 \mathrm{~mm}$.

\subsection{New greenhouse structure}

The new greenhouse structure comprised the same parts as those of the conventional greenhouse. However, the manner of arrangement was different from the conventional structure. We aligned 10 tilted arch pipes at $500 \mathrm{~mm}$ intervals. These tilted arch pipes were connected by five straight pipes. Fig. 3 shows the 3D tilted arch pipes. The pipe material and the number of pipe parts are the same as those in the conventional greenhouse. Therefore, the material costs, number of connected points, and workability were the same as those in the conventional greenhouse. The structure was based on the truss structure.

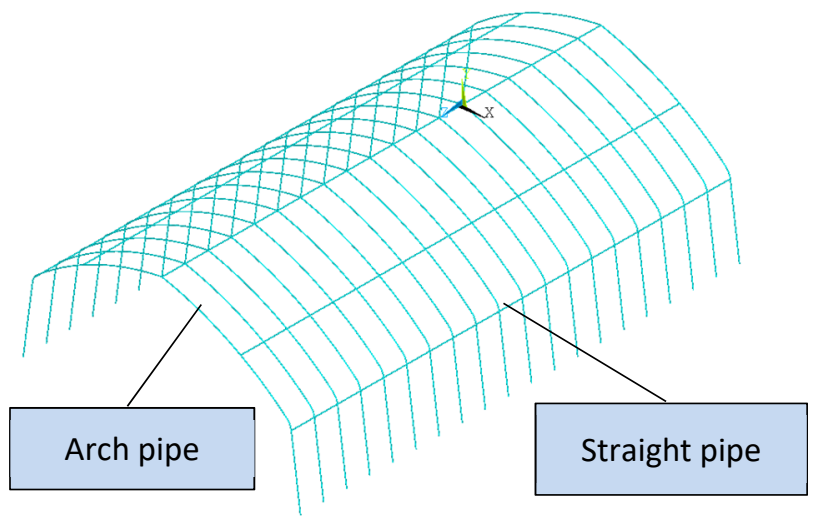

Figure 2: $3 \mathrm{D}$ structure of a conventional greenhouse.

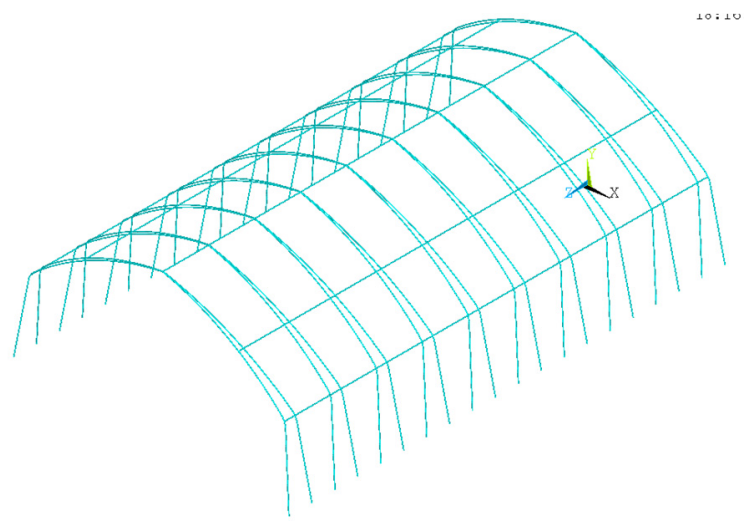

Figure 3: $\quad 3 D$ structure of the new greenhouse. 


\section{Eigenvalue analysis}

\subsection{Analysis methods}

We used ANSYS 17.0 (ANSYS Inc.) for the eigenvalue analysis. The model was made by a beam element. A section of the element has an external diameter of 22.2 $\mathrm{mm}$ and a thickness of $1.2 \mathrm{~mm}$. The ground-embedded parts were fixed. Therefore, the three direction displacements had zero as a constraint condition. We adapted the frequency range from $0 \mathrm{~Hz}$ to $10 \mathrm{~Hz}$. This range was calculated by $35.9 \mathrm{~m} / \mathrm{s}$, which was the 10 minutes' average wind speed at an altitude of $10 \mathrm{~m} \mathrm{[7].}$

\subsection{Analysis results and consideration}

Table 1 shows the eigenvalues of the conventional and new structures. The number of the eigenmodes in the new structure was less than that of the conventional structure between $0 \mathrm{~Hz}$ and $10 \mathrm{~Hz}$. Fig. 4 shows the deformation of eigenmode shape 3. Fig. 5 shows the deformation of eigenmode shape 13. The shapes of eigenmodes 3 and 13 of the conventional structure could not be found out in the new structure by approximately $10 \mathrm{~Hz}$. We considered that these eigenmodes were transferred to a higher frequency range of over $10 \mathrm{~Hz}$. Fig. 6 shows the deformation of eigenmode shape 7 . Fig. 7 illustrates the deformation of eigenmode shape 13. A shape of eigenmode 7 of the conventional structure could be determined in a shape of eigenmode 13 of the new structure. The frequency of eigenmode 13 of the new structure was close to $10 \mathrm{~Hz}$. We considered that the eigenmode was transferred to a high-frequency range.

Consequently, the new structure reduced the eigenmode to $10 \mathrm{~Hz}$. The low frequency eigenmode was transferred to a high frequency. These phenomena were caused by the higher rigidity. Therefore, the risk of collapse by resonance was reduced.

Table 1: $\quad$ Natural frequency of the conventional and new structures.

\begin{tabular}{|c|c|c|c|c|c|}
\hline \multirow{2}{*}{$\begin{array}{c}\text { Eigenmode } \\
\text { nos. }\end{array}$} & \multicolumn{2}{|c|}{ Frequency $[\mathrm{Hz}]$} & \multirow{2}{*}{$\begin{array}{c}\text { Eigenmode } \\
\text { nos. }\end{array}$} & \multicolumn{2}{c|}{ Frequency [Hz] } \\
\cline { 2 - 3 } & Conventional & New & Conventional & New \\
\hline 1 & 1.2757 & 1.3099 & 10 & 7.0000 & 8.2206 \\
\hline 2 & 1.8297 & 2.8515 & 9 & 6.7017 & 7.9453 \\
\hline 3 & 2.0712 & 3.6655 & 11 & 8.0015 & 8.4735 \\
\hline 4 & 3.6574 & 3.7132 & 12 & 8.2271 & 9.4082 \\
\hline 5 & 3.7994 & 5.2040 & 13 & 8.8723 & 9.4377 \\
\hline 6 & 4.6791 & 5.1820 & 14 & 9.0315 & 9.5405 \\
\hline 7 & 4.6979 & 6.0710 & 15 & 9.0835 & 9.9129 \\
\hline 8 & 5.3893 & 7.4073 & 16 & 9.3508 & \\
\hline
\end{tabular}




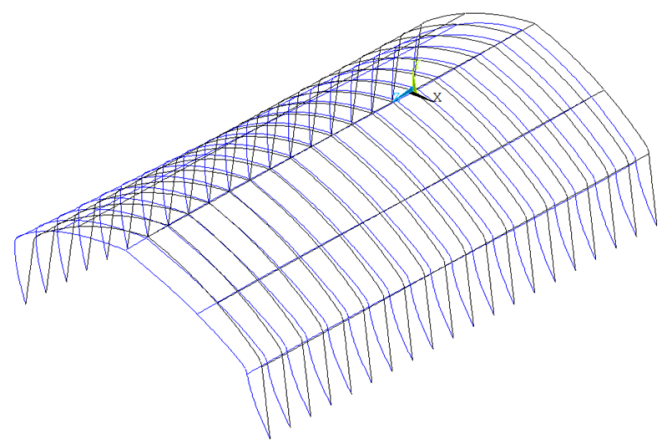

(a) Isometric view.

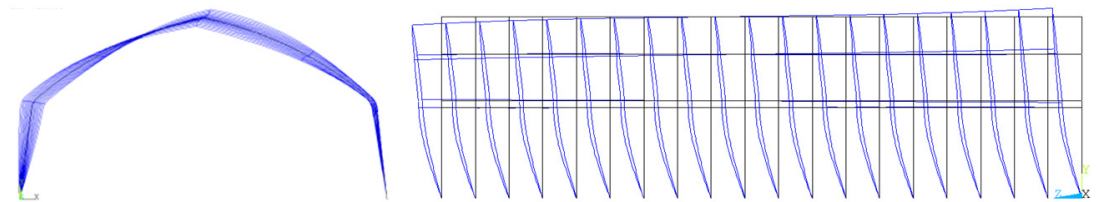

(b) $\mathrm{Z}$ axis direction view.

(c) $\mathrm{X}$ axis direction view.

Figure 4: Deformation form of eigenmode 3 of the conventional structure.

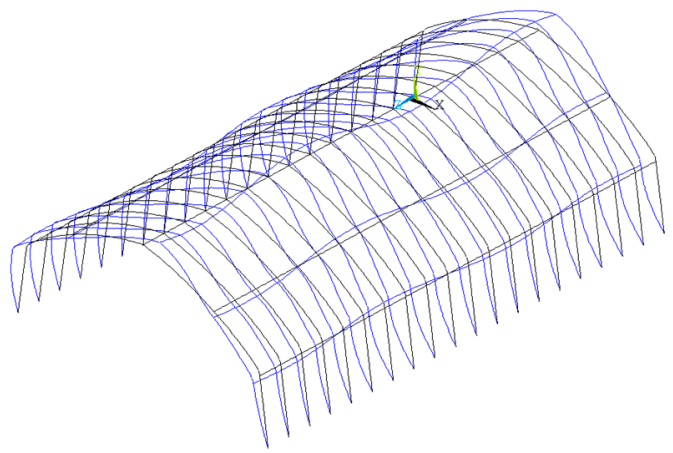

(a) Isometric view.

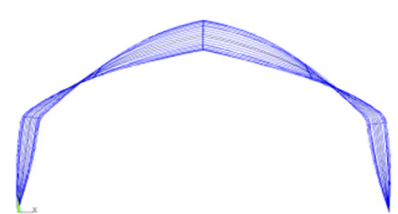

(b) $\mathrm{Z}$ axis direction view.

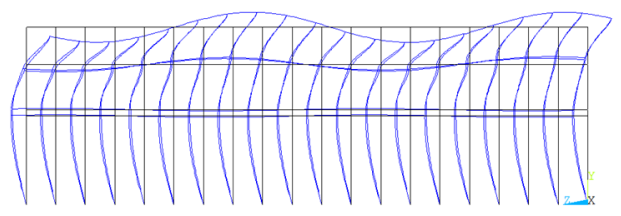

(c) $\mathrm{X}$ axis direction view.

Figure 5: Deformation form of eigenmode 13 of the conventional structure. 
78 High Performance and Optimum Design of Structures and Materials II

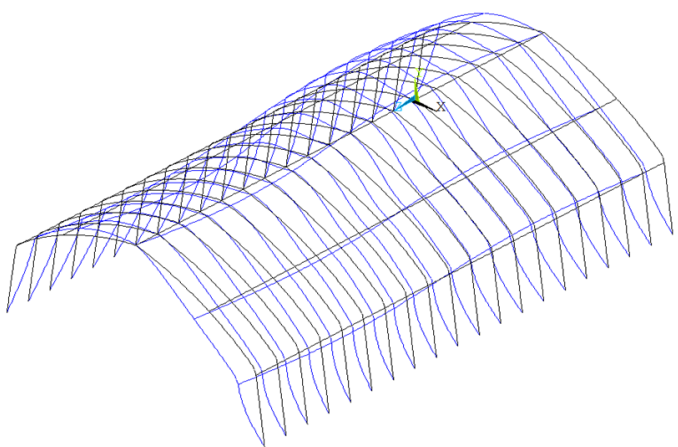

(a) Isometric view.

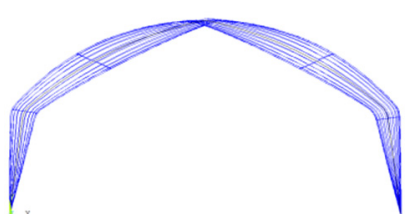

(b) $\mathrm{Z}$ axis direction view.

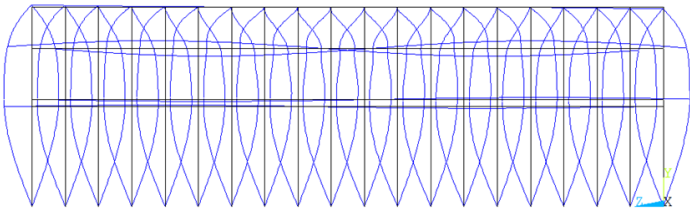

(c) $\mathrm{X}$ axis direction view.

Figure 6: Deformation form of eigenmode 7 of the conventional structure.

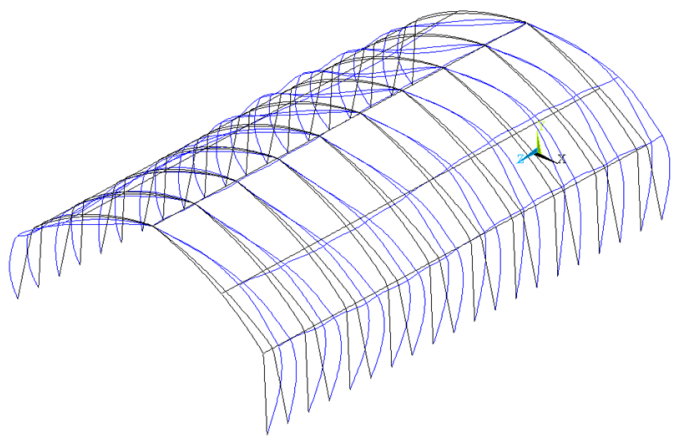

(a) Isometric view.

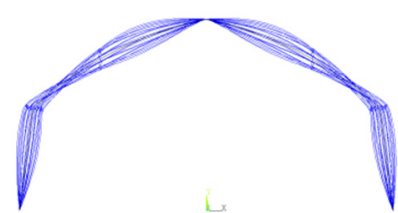

(b) $\mathrm{Z}$ axis direction view.

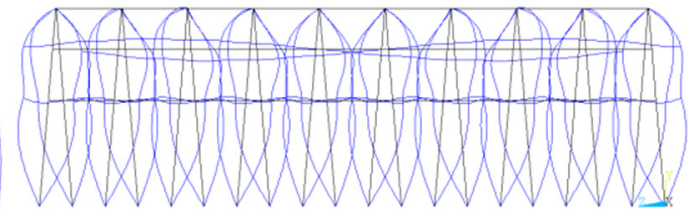

(c) $\mathrm{X}$ axis direction view.

Figure 7: Deformation form of eigenmode 13 of the new structure. 


\section{Conclusions}

This paper proposed a new greenhouse structure based on the truss structure. The new greenhouse had the same material costs and workability as that of the conventional one. We analysed the eigenvalue of both the conventional and new greenhouses. Consequently, we found that the new structure has a higher rigidity than the conventional structure. Therefore, the new structure is an efficient measure against typhoon and collapse possibilities. In addition, the new structure shows strong resistance against resonance.

\section{References}

[1] Japan Greenhouse Horticulture Association, Standard for Structures of Greenhouses, Japan Greenhouse Horticulture Association: Japan, 1999.

[2] Obata, A., Uematsu, Y., Nakahara, K. \& Matsumoto, S., Study of wind pressures on greenhouses based on full-scale measurements (Part 1: Outline of full-scale measurements and average wind pressure coefficients), Summaries of technical papers of annual meeting Architectural Institute of Japan, Architectural Institute of Japan: Japan, pp. 103-104, 2007 (in Japanese).

[3] Toyoda, H., Moriyama, H., Seno, T. \& Maekawa, T., Examples and Characteristics of wind damages on plastic greenhouse, Journal of the Society of Agricultural Structures, The Society of Agricultural Structures: Japan, pp. 21-30, 1998, (in Japanese with English abstract).

[4] Fujiwara, R., Miyamoto, M. \& Matsushita, M., Estimation of Wind Load to Pipe-framed Greenhouse Based on Wind Observation, Summaries of technical papers of annual meeting Architectural Institute of Japan, Architectural Institute of Japan: Japan, pp. 155-156, 2013 (in Japanese).

[5] Moriyama, H., Mears, D. R., Sase, S., Ikeguchi, A. \& Yamaguchi, T., Reinforcement for Pipe-Framed Greenhouse under Snow Load and Design Optimization Considering Steel Mass, Journal of the Society of Agricultural Structures, The Society of Agricultural Structures: Japan, pp. 263-274, 2008 (in Japanese with English abstract).

[6] Kwon, K., Kim, D., Kim, R., Ha, T. \& Lee, I., Evaluation of wind pressure coefficients of single span greenhouses built on reclaimed coastal land using a large-sized wind tunnel, Biosystems Engineering I4I, Elsevier Ltd: Amsterdam, pp. 58-81, 2016.

[7] Japanese Electro-technical Committee, JEC-127, The Institute of Electrical Engineers of Japan: Japan, 1979. 